\section{BMJ Open Sport \& Exercise Medicine}

\title{
A randomised controlled trial of long- chain omega-3 polyunsaturated fatty acids in the management of rotator cuff related shoulder pain
}

\author{
Fiona M Sandford, ${ }^{1}$ Thomas A Sanders, ${ }^{2}$ Hannah Wilson, ${ }^{3}$ Jeremy S Lewis ${ }^{4,5}$
}

\begin{abstract}
To cite: Sandford FM, Sanders TA, Wilson $\mathrm{H}$, et al. A randomised controlled trial of long-chain omega-3 polyunsaturated fatty acids in the management of rotator cuff related shoulder pain. $B M J$ Open Sport \& Exercise Medicine 2018;4:e00414. doi:10.1136/ bmjsem-2018-000414
\end{abstract}

Accepted 25 June 2018

Check for updates

(C) Author(s) (or their employer(s)) 2018. Re-use permitted under CC BY-NC. No commercial re-use. See rights and permissions. Published by BMJ.

${ }^{1}$ Guys and St Thomas' NHS Foundation Trust, Hand Therapy Department, London, UK

${ }^{2}$ King's College London, Department of Nutritional Sciences, London, UK ${ }^{3}$ Royal Free London NHS Foundation Trust, Physiotherapy Department, London, UK ${ }^{4}$ School of Health and Social Work, University of Hertfordshire, Hatfield, UK

${ }^{5}$ Central London Community Healthcare, NHS Trust, London, UK

Correspondence to Dr Fiona M Sandford; fiona. sandford@gstt.nhs.uk

\section{ABSTRACT}

Study design Multicentre, double-blind, placebocontrolled randomised clinical trial.

Objectives To compare the effectiveness of long chain omega-3 polyunsaturated fatty acids (PUFAs) as part of the management for people diagnosed with rotator cuff related shoulder pain (RCRSP).

Summary of background Although there is no robust evidence to support their use, omega-3 PUFAs have been recommended for those with tendinopathy due to their potential to moderate inflammation.

Methods Participants with RCRSP $(n=73)$ were randomised to take either nine MaxEPA capsules providing $1.53 \mathrm{~g}$ eicosapentaenoic acid, $1.04 \mathrm{~g}$ docosahexaenoic acid or nine matching placebo capsules containing oleic acid per day for 8 weeks. In addition, participants attended an exercise/education programme for 8 weeks. Participants were assessed at prerandomisation, 8 weeks (primary outcome point), 3 months, 6 months and 12 months (secondary outcome point). Primary outcome was the Oxford Shoulder Score (OSS). Secondary outcomes included the Shoulder Pain and Disability Index (SPADI), Patient Specific Functional Score, Euro Qol 5D-3L, Short Form 36, global rating of change and impairment measurements. Analysis was by intention to treat. Results Difference in the change in the OSS between the two groups at 2 months was $-0.1(95 \% \mathrm{Cl}-2.6$ to $2.5, p=0.95)$. The change in SPADI scores was -8.3 $(95 \% \mathrm{Cl}-15.6$ to $-0.94, \mathrm{p}=0.03$, analysed by analysis of covariance adjusted for baseline) at 3 months.

Conclusion Omega-3 PUFA supplementation may have a modest effect on disability and pain outcomes in RCRSP.

\section{INTRODUCTION}

Rotator cuff related shoulder pain (RCRSP) is characterised by pain and dysfunction arising from one or more of the rotator cuff tendons ${ }^{1}$ and maybe associated with longterm morbidity and functional loss. The reported life time incidence of RCRSP may reach $67 \%^{23}$ and the annual incidence over $1 \%{ }^{45}$ Many continue experiencing pain and functional disability for up to 1 year, ${ }^{6-8}$ and over $50 \%$ of individuals experience continued pain after 3 years. ${ }^{9}$
What are the new findings?

- The effect of taking omega-3 polyunsaturated fatty acid (PUFA) supplements on disability and pain outcomes in people with rotator cuff related shoulder pain (RCRSP) is no greater than placebo.

- Change in self-reported pain and disability scores was similar between groups over all outcome points and is linked to the exercise intervention (or another mechanism such as natural improvement) rather than omega-3 PUFA supplements.

- Further research is warranted to determine whether higher doses, longer duration doses or earlier intervention of omega-3 PUFA regimes would influence disability and function in RCRSP.

How might it impact on clinical practice in the near future?

Clinicians can be confident that class and home ex ercise prescription without the addition of omega-3 PUFA supplements provides improvement in function and reduction in pain over time in those presenting with RCRSP.

Much is still unknown about the pathophysiology and management of RCRSP. One hypothesis considers involvement of inflammation in the pathoaetiology and symptomology. ${ }^{10}$ The accumulation of inflammatory cells in human tendons ${ }^{11-13}$ and in animal models, ${ }^{14}{ }^{15}$ coupled with increased levels of proinflammatory cytokines evident in tendinopathic rotator cuff tissue ${ }^{16-18}$ may support this hypothesis. Advice, education and graduated exercise forms the main RCRSP management, and although demonstrate equivalent outcomes to surgery, ${ }^{19} 20$ incomplete symptom resolution is common. Subsequently, other interventions must be considered.

The rationale underpinning fish oil supplementation in RCRSP lies in the anti-inflammatory effects of omega-3 
polyunsaturated fatty acids (PUFAs). ${ }^{21}$ While omega-3 PUFAs have been found to have beneficial effects on a range of inflammatory conditions, ${ }^{22}$ the results cannot be directly translated to RCRSP.

Two previous trials have reported conflicting findings regarding efficacy of omega-3 PUFAs for tendinopathy treatment. ${ }^{23}$ While the potential for dietary supplementation of omega-3 PUFAs and antioxidants to reduce disability and morbidity associated with RCRSP is appealing, it has not yet been formally investigated. ${ }^{21}$

The primary aim of this RCT was to assess whether 2 months supplementation with omega-3 PUFAs combined with exercise, conferred any benefit (measured by pain reduction and improved disability and function) over a placebo and the same exercise programme in RCRSP management.

\section{MATERIALS AND METHODS Design}

Multicentre, two armed, double-blind, randomised placebo controlled clinical trial (ISRCTN17856844).

Seventy-three participants were recruited from three secondary care and one primary care National Health Service (NHS) physiotherapy departments in London, UK. Inclusion criteria include $18-80$ years, a 3-month or greater history of unilateral shoulder pain, pain produced or increased during shoulder flexion and/or abduction and/or external rotation of the symptomatic shoulder and a minimum of four of the following: positive Neer's impingement sign, positive Hawkins and Kennedy test, pain and weakness reproduced on full and/or empty can test, pain and weakness on resisted shoulder external rotation and pain on palpation over greater tuberosity of the humerus. Exclusion criteria include allergy/ unwilling to take fish oils or currently taking over $1 \mathrm{~g}$ /day of fish oils, diabetes, pregnancy or breast feeding, reproduction of shoulder symptoms during active cervical spine movements, post-traumatic onset of symptoms, radiographic or clinical evidence of shoulder instability (sulcus, anterior/posterior draw, relocation test, apprehension test).

\section{Patient involvement}

Patients were involved in outcome measure selection and burden of the assessment. Patients were not involved at the study design stage or in the recruitment or conduct of the study. A one-page synopsis of the study results will be disseminated to the participants via mail or email.

\section{Consent and randomisation}

Participants provided written informed consent prior to study enrolment and were randomly assigned using predetermined computer-generated codes into allocated groups. Concealment to group allocation was via serially numbered opaque envelopes, produced by a third party who held the randomisation codes. The chief investigator and participants remained blind to group allocation for study duration until all data had been entered into the statistical database.

\section{Intervention}

MaxEPA (Seven Seas Ltd, Hull, UK, MHRA product licence 19488/0353) soft shell capsules containing 170 mg eicosapentaenoic acid (EPA), $115 \mathrm{mg}$ docosahexaenoic acid (DHA) and 2 units/g tocopherols acetate (vitamin E) were provided. The placebo supplement was identical in appearance and contained a mixed inert oil (olive oil BP containing the same amount of vitamin $\mathrm{E}$ and antioxidants as the active treatment), EPA and DHA being replaced by oleic acid. Both group's participants were asked to take nine capsules daily for 2 months and recommended to take the capsules with meals to minimise any gastrointestinal irritation. Participants were requested to return any unused capsules at the end of the study.

All participants attended weekly, hour long RCRSP exercise and education groups, for 8 weeks.

The exercises aimed to improve strength and sensorimotor control of the shoulder and included lower limb exercises. Physiotherapists delivered manual therapy shoulder techniques, determined pragmatically based on what was considered most appropriate for approximately $1 \mathrm{~min}$.

Participants were assessed by the chief investigator or research assistant at baseline, 8 weeks, 3 months, 6 months and 1 year.

Outcome measures completed included:

1. Disability: Oxford Shoulder Score (OSS) and Shoulder Pain and Disability Index (SPADI).

2. Pain: Numerical Rating Scale (NRS) and Short Form (SF) 36 bodily pain (BP) domain.

3. Quality of life: SF 36 and Euro Qol 5D-3 L.

4. Function: Patient Specific Functional Score (PSFS).

5. Global perception of change score.

6. Impairment measures; shoulder range of motion and strength.

Plasma fatty acids, capsules returned and self-report numbers of capsules taken were used as measures of adherence with the supplement intervention. Exercise class attendance and documentation of home exercises undertaken gave an indication regarding adherence with exercise intervention.

Sample size calculations were based on a change in OSS as the primary outcome. When designing the study, the minimal clinically important difference was not published for the OSS, but from previous work ${ }^{25}$ it was estimated to be five which is equivalent to a $21 \%$ change from the midpoint of the scale (0-48). A change of six has recently been shown to be the minimal important difference and smallest detectable change for the OSS. ${ }^{26}$ The SD of the OSS is $5.87 .^{25}$ The sample size was calculated to be 29 subjects in each of the two groups (58 in total), to detect a five-point change at $\mathrm{p}<0.05$ with a $90 \%$ power. Allowing for a dropout rate of $10 \%,{ }^{6}$ the study aimed to randomise 32 participants to each group.

Adverse events were defined as intervention side effects requiring medical intervention. 


\begin{tabular}{|c|c|c|}
\hline Variable & $\begin{array}{l}\text { Placebo } \\
(n=35)\end{array}$ & $\begin{array}{l}\text { Treatment } \\
(n=38)\end{array}$ \\
\hline Gender: male & $20(57.1 \%)$ & $17(44.7 \%)$ \\
\hline Age (years) & $52.0(16.2)$ & $52.2(12.0)$ \\
\hline Body mass index $\left(\mathrm{kg} / \mathrm{m}^{2}\right)$ & $28.9(8.4)$ & $27.5(5.2)$ \\
\hline Waist circumference (cm) & $98.8(16.4)$ & $94.8(13.0)$ \\
\hline Current smoker & $5(14.3 \%)$ & $5(14.3 \%)$ \\
\hline $\begin{array}{l}\text { Plasma eicosapentaenoic acid } \\
\text { and docosahexaenoic acid } \\
\text { (wt\%) }\end{array}$ & $3.9(1.5)$ & $4.1(1.8)$ \\
\hline Analgesia medication & $10(28.6 \%)^{*}$ & $3(7.9 \%)$ \\
\hline Statin medication & $7(20 \%)$ & $6(15.8 \%)$ \\
\hline Symptom duration (months) & $10(4-18)$ & $9(6-19.5)$ \\
\hline \multicolumn{3}{|l|}{ Mechanism of injury } \\
\hline Insidious & $17(48.6 \%)$ & $21(55 \%)$ \\
\hline Accident/fall & $5(14.3 \%)$ & $8(21.1 \%)$ \\
\hline Lifting/repetitive movement & $6(17.1 \%)$ & $6(15.8 \%)$ \\
\hline Exercise & $7(20.0 \%)$ & $3(7.9 \%)$ \\
\hline $\begin{array}{l}\text { Able to sleep on symptomatic } \\
\text { shoulder }\end{array}$ & $17(48.6 \%)$ & $17(44.7 \%)$ \\
\hline
\end{tabular}

Summary measures represent means/N (SD/\%/range). Differences between groups test with Mann-Whitney test or $\chi^{2}$ test.

${ }^{*} \mathrm{P}=0.03$

wt $\%$, weight percentage.

\section{Statistical analysis}

Statistical analysis of the data was conducted using SPSS for windows V.22.0 (IBM Software, Hampshire, UK). Standard distributional checks were made, and where appropriate, analyses were attempted following log transformation.

The data was analysed on an intention-to-treat basis. Analysis of covariance (ANCOVA) tests were conducted for within-subject factor (assessment time point) and between-group factor (supplement type; placebo or treatment) with OSS as the dependent variable, the treatment allocation as the predictor factor, age, gender and body mass index as covariates and the baseline OSS as an offset variable. A mixed-model ANCOVA analysis was also used to look for change over the whole study period in each outcome measure adjusting for the baseline measurements. Similar analyses were conducted for secondary outcomes efficacy analysis: ANCOVA and mixed-model ANCOVA.

\section{RESULTS}

Seventy-three participants were consented between December 2008 and January 2013, when precalculated sample reached. More participants in the placebo group reported use of analgesic medication $\left(\mathrm{p}=0.02 ; \chi^{2}\right.$ test $)$. There were no other significant differences in baseline characteristics or outcome measures between groups (table 1).
At the primary outcome point at 2 months, 71 (96\%) participants were reassessed, and at 12 months, 65 (89\%) participants were reassessed. There was no statistically significant difference in the attrition rate between groups (figure 1).

\section{Adherence to the interventions}

No significant difference in intervention adherence was found between groups. There was a statistically significant difference in the blood plasma levels of omega-3 PUFAs (EPA and DHA) at the end of the intervention between the two groups (mean difference $=2.4$, 95\% CI 1.6 to $3.1, \mathrm{p}<0.001$ ) (figure 2 ).

Both groups demonstrated a significant reduction in disability, as measured by the OSS. There was on average a $25 \%$ reduction in disability (95\% CI 15.3 to 34.6 ; mean difference $=8.2$ ) in the placebo group and $25 \%$ reduction (95\% CI 13.5 to 36.2; mean difference $=6.7$ ) in the intervention group at 2 months (table 2).

No statistically significant difference was found in the change in the primary outcome, OSS, between the two groups at 2 months (adjusted mean difference $=-0.1,95 \%$ CI -2.6 to $2.5, \mathrm{p}=0.95$ ) and up to 12 months (adjusted mean difference $=-0.3,95 \%$ CI -3.3 to $2.6, \mathrm{p}=0.82$ ) (table 2, figure 3 )

A statistically significant reduction in level of perceived disability as measured by SPADI was observed in both groups (2 months: placebo mean difference $=16.9$, 95\% CI 10.9 to $22.9, \mathrm{p}=0.00$ and omega-3 PUFA mean difference $=15.9,95 \%$ CI 9.5 to $22.2, p=0.00 ; 12$ months: placebo mean difference $=15.795 \%$ CI 8.2 to $23.3, \mathrm{p}=0.00$ and omega-3 PUFA mean difference $=7.8,95 \%$ CI 0.9 to 14.71, $\mathrm{p}=0.03$ ).

The PUFA supplement group showed a statistically significant change when compared with the placebo group (adjusted mean difference $=-8.6,95 \%$ CI -15.6 to $-0.9, \mathrm{p}=0.03$, analysed by ANCOVA adjusted for baseline) at 3 months (table 2, figure 4 ).

A statistically significant reduction in pain was reported by both groups at the primary outcome point (NRS $(\mathrm{p}<0.01)$ and the SF 36 BP $(\mathrm{p}<0.01)$ component $)$. At 2 months, the placebo group demonstrated a 2.2 point reduction (95\% CI 1.2 to 3.1), and the omega-3 PUFA group demonstrated a 2.1 point reduction $(95 \%$ CI 0.04 to 2.3 ) in the NRS.

No statistically significant differences were found between the groups for the secondary outcomes when compared at any follow-up point (table 2 and table 3 ).

There were significant differences found in shoulder abduction and flexion range of motion between the two groups $(\mathrm{p}<0.01)$ in favour of the treatment group (flexion mean difference $=7.7^{\circ}, 95 \%$ CI 2.4 to 12.9 , abduction mean difference $=10.4^{\circ}, 95 \%$ CI 3.1 to 17.7 ). These differences may not be clinically important. Shoulder external rotation strength at 12 months was also found to be statistically significantly different between groups in favour of the treatment group $(\mathrm{p}<0.01)$. 


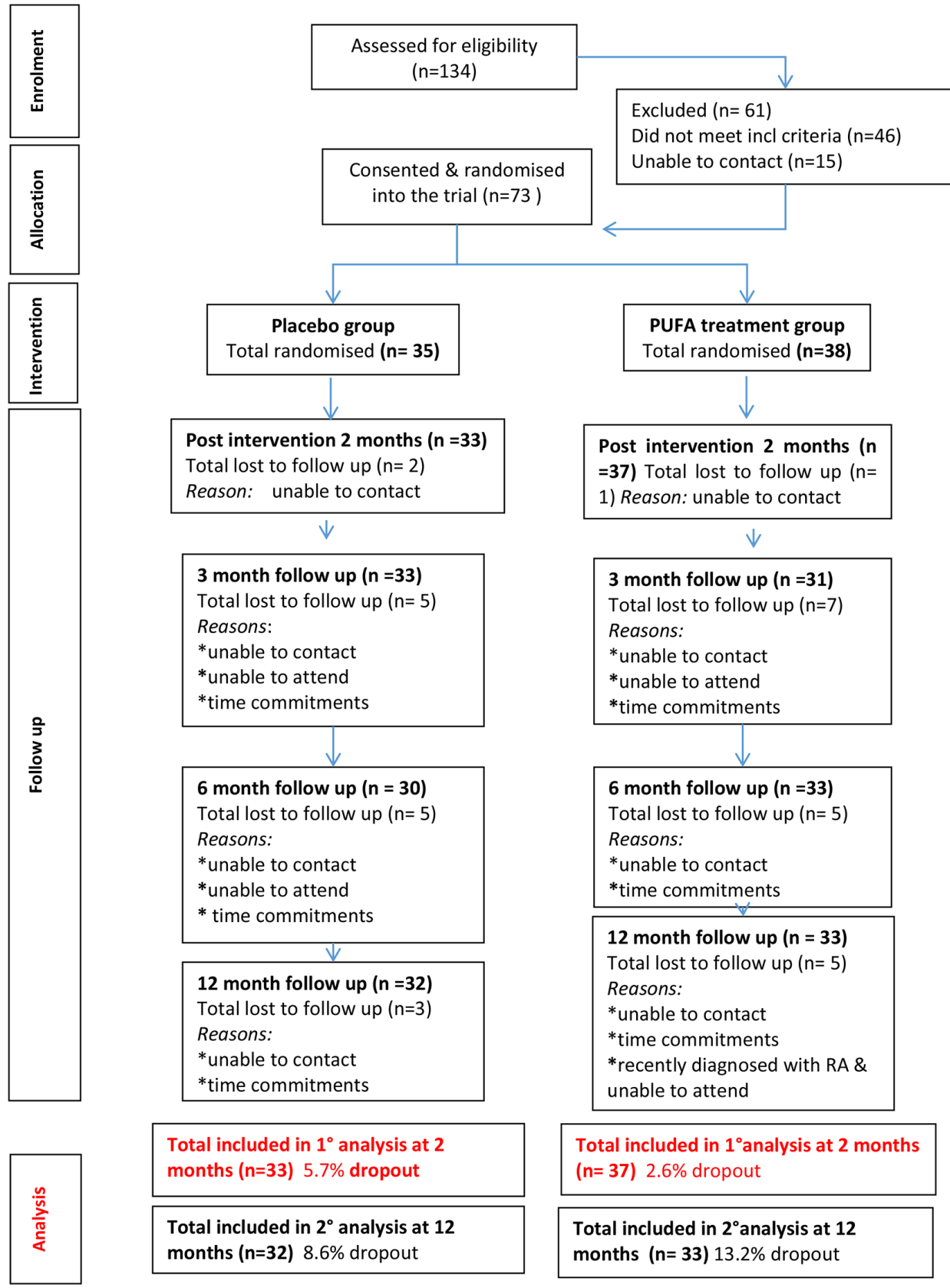

Figure 1 Consort diagram.

There were no statistically significant differences in pretrial and post-trial fatty acid intakes for the participants (estimated from 4-day food diaries).

No serious adverse events were reported.

A post hoc analysis of the effect of increased EPA and DHA within the plasma and the improvement in disability and pain at the primary outcome point of 2 months using regression and partial correlations adjusted for treatment group was conducted. A relationship between increasing EPA and DHA plasma levels and decreasing reported pain as measured by the NRS was found (correlation $-31 \%$ for EPA and $32 \%$ for DHA, $\mathrm{p}=0.01$ for both EPA and DHA). For each unit increase of EPA and DHA, there was on average a $9 \%$ and $14 \%$ change observed in the NRS score, respectively.

\section{DISCUSSION}

This study investigated the efficacy of omega-3 PUFA supplements alongside an exercise intervention for RCRSP. Study results demonstrated statistically and clinically significant improvements in disability and pain in both group's participants at 2, 3, 6 and 12 months. The omega-3 PUFA group demonstrated a more rapid improvement in disability of $64 \%$ improvement from baseline at 3 months, compared with a $42 \%$ in the placebo group on secondary outcome measure (SPADI). However, no discernible difference was noted between the two groups in OSS and NRS scores and so may be an anomaly, further investigation would be indicated.

Two previous randomised controlled trials investigating the efficacy of omega-3 PUFA supplements and 


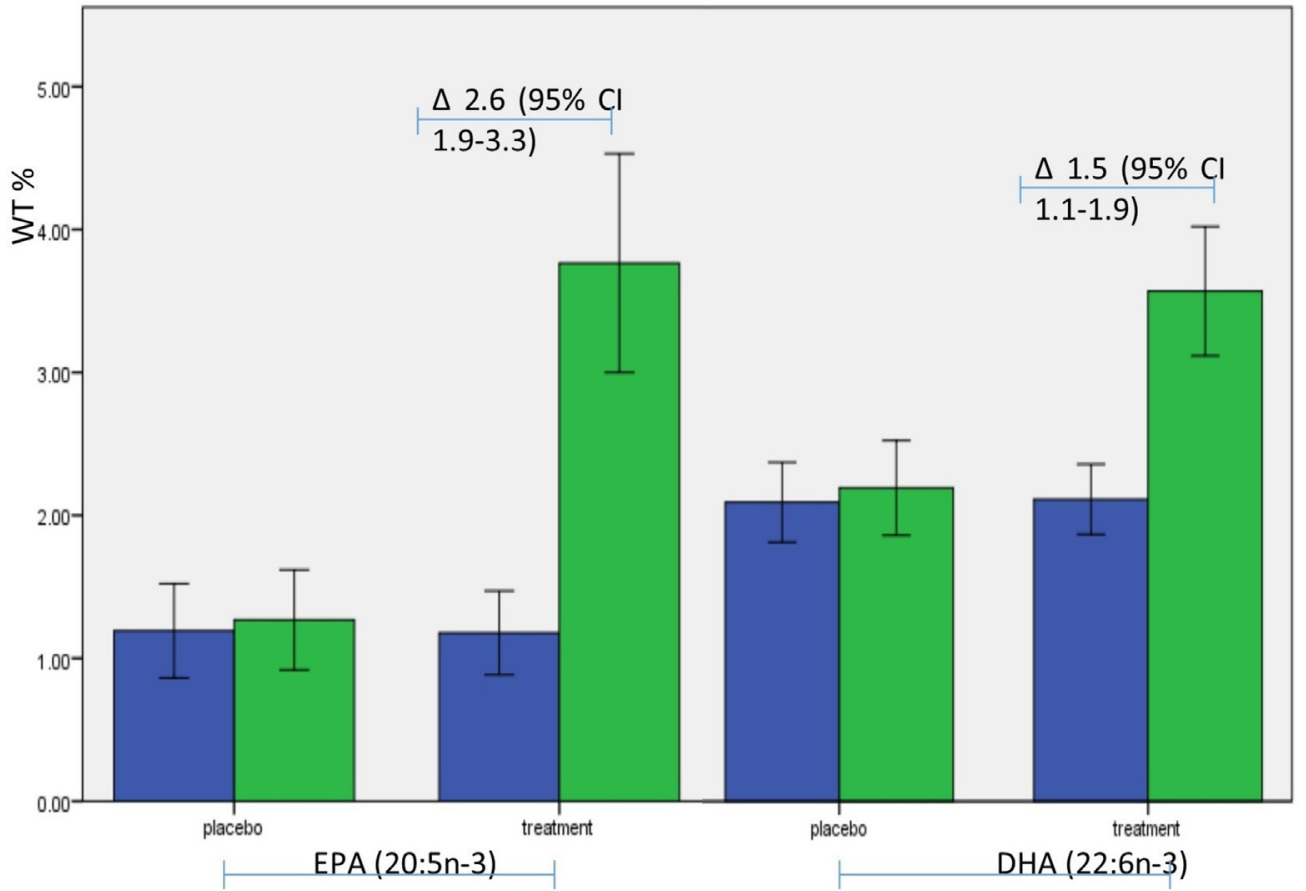

Figure 2 Graph showing the rise in EPA and DHA plasma levels within the treatment group, within group comparisons made using a paired samples t-test. DHA, docosahexaenoic acid; EPA, eicosapentaenoic acid; wt\%, percentage weight; $\Delta$, mean difference and $95 \% \mathrm{Cl}$ between baseline and follow-up.

tendinopathies were identified. ${ }^{23}{ }^{24}$ Mavrogenis et als double-blinded study reported a significant improvement in pain after 32 days of supplementation with omega-3 PUFA and an antioxidant pill in recreational athletes with tendinopathies. ${ }^{21}$ However, methodological limitations included participant selection bias, an absence of intention to treat $^{27}$ and broad inclusion criteria. Poor clarity surrounding confounding factors, including the implications of using ultrasound in treatment packages further limited the potential impact of findings.

Roe et al, using an omega-3 PUFA supplement and antioxidant pill for 56 days on subjects with lateral elbow tendinopathy, found no statistically significant differences in pain at either week 8 or 24. Methodological differences between the three studies may explain the discrepancies in the outcomes and conclusions. Mavrogenis $e t a l^{23}$ did not use an intention-to-treat analysis, and $23 \%$ of subjects were excluded. Furthermore, the mean duration of symptoms reported by Mavrogenis $e t a l^{23}$ was 6 months compared with the current study (9 months) and that of Roe et al (18 months). Poorer outcomes are associated with longer duration of symptoms ${ }^{28}$ raising the possibility that supplementation at an earlier stage may be of greater benefit. This is purely speculative, and the hypothesis requires testing. Additionally, all studies involved different treatments in the experimental groups.

No study included a non-treatment control group. Therefore, the improvements in reported disability may be due to regression to the mean, ${ }^{29}$ the immediate or longer term effects of exercise, other treatments or the immediate or longer term influence of the supplements.
The dosage of $2.6 \mathrm{~g}$ omega-3 PUFA per day was lower than the $5.1 \mathrm{~g}$ in the studies conducted both by Mavrogenis $e t a l^{23}$ and Roe $e t$ al. While positive effects were noted at that dose given in the Mavrogenis $e t a l \mathrm{~s}^{23}$ experimental group, similar outcomes were not reported by Roe $e t a l$, indicating the positive outcome in the Mavrogenis $e t a l \mathrm{~s}^{23}$ study cannot be explained by dosage alone. Omega-3 PUFA (2.6 g) was selected in the present study based on the lower predicted efficacy level of omega-3 PUFA in the previous trials. ${ }^{30}$

The relationship observed in this study with EPA and DHA and pain (as measured by NRS) supports the argument of investigating the efficacy of higher doses of omega-3 PUFA.

Adherence to the intervention was good; capsules returned matched reported consumption and significant increases in the proportions of EPA and DHA in plasma lipids provide independent verification. There were, however, considerable variations in the extent of the increases in EPA and DHA within the participants allocated to the intervention group possibly reflecting different body sizes and other fatty acids, particularly omega- 6 fatty acids, in their background diet. The increases in EPA and DHA are comparable with other studies that have used intakes of omega- 3 PUFA in the range of $2-3 \mathrm{~g} / \mathrm{d} .{ }^{31}$ MaxEPA which was used in the present study contains in total approximately $35 \%$ longchain omega-3 fatty acids (including 18:4 n-3, 20:4 n-3, 22:5 n-3), with EPA and DHA typically providing $18 \%$ and $12 \%$ of the fatty acids. Allowing for the non-fatty acid components, the calculated intake of total long-chain 
Table 2 Outcome measures during the course of the trial Intervention group

\begin{tabular}{|c|c|c|}
\hline \multirow[b]{2}{*}{ Outcome measure } & \multicolumn{2}{|l|}{ Intervention group } \\
\hline & Placebo & $\begin{array}{l}\text { Omega-3 } \\
\text { polyunsaturated } \\
\text { fatty acids }\end{array}$ \\
\hline \multicolumn{3}{|c|}{ Disability (Oxford Shoulder Score, 0-48; 48 best) } \\
\hline Baseline & 31.7 (28.9 to 34.5$)$ & $32.0(29.5$ to 34.5$)$ \\
\hline 2 months & 39.9 (37.5 to 42.4$)$ & 38.7 (36.1 to 41.3$)$ \\
\hline 3 months & 39.5 (37.1 to 41.8$)$ & 40.5 (37.9 to 43.1$)$ \\
\hline 6 months & 42.1 (40.4 to 43.8$)$ & 41.6 (39.2 to 44.1$)$ \\
\hline 12 months & 43.1 (41.2 to 45.0$)$ & $43.0(40.7$ to 45.4$)$ \\
\hline \multicolumn{3}{|c|}{$\begin{array}{l}\text { Disability (Shoulder Pain and Disability Index, 0-100; } \\
0=\text { best) }\end{array}$} \\
\hline Baseline & $43.1(21.5)$ & 38.7 (22.3) \\
\hline 2 months & $25.1(22.8)$ & $23.4(23.1)$ \\
\hline 3 months & $25.3(21.1)$ & $13.9(18.1)^{\star}$ \\
\hline 6 months & $16.9(18.3)$ & $13.3(19.0)$ \\
\hline 12 months & $9.9(2.4)$ & $11.2(19.2)$ \\
\hline \multicolumn{3}{|c|}{$\begin{array}{l}\text { Function (Patient Specific Functional Score 0-100; } 100 \\
\text { best) }\end{array}$} \\
\hline Baseline & 38.4 (31.8 to 44.9$)$ & 36.8 (30.3 to 43.3 ) \\
\hline 2 months & 58.4 (50.2 to 66.6$)$ & 64.6 (56.8 to 72.3$)$ \\
\hline 3 months & $68.9(61.0$ to 76.8$)$ & 72.0 (64.6 to 79.5$)$ \\
\hline 6 months & 72.9 (65.3 to 80.5$)$ & 76.6 (69.3 to 83.8$)$ \\
\hline 12 months & 78.8 (70.6 to 87.0) & 80.4 (73.0 to 87.9$)$ \\
\hline \multicolumn{3}{|c|}{ Pain (Numerical Rating Scale, 0-10; 0=best) } \\
\hline Baseline & $6.3(5.7$ to 6.9$)$ & 6.0 (5.3 to 6.7$)$ \\
\hline 2 months & 4.0 (3.2 to 4.8$)$ & $3.8(2.9$ to 4.6$)$ \\
\hline 3 months & 3.5 (2.6 to 4.4$)$ & 2.6 (1.8 to 3.3$)$ \\
\hline 6 months & 3.3 (2.3 to 4.3$)$ & 2.9 (2.0 to 3.7$)$ \\
\hline 12 months & $2.1(1.3$ to 2.9$)$ & $2.1(1.2$ to 3.0$)$ \\
\hline \multicolumn{3}{|c|}{ Pain (Short Form 36 bodily pain, 0-100; 100=best) } \\
\hline Baseline & $47.9(41.6$ to 54.2$)$ & $51.6(44.7$ to 58.5$)$ \\
\hline 2 months & 64.7 (57.8 to 71.5$)$ & $67.3(61.4$ to 73.2$)$ \\
\hline 3 months & $62.2(55.1$ to 69.4$)$ & $71.1(64.3$ to 77.8$)$ \\
\hline 6 months & 73.4 (66.8 to 79.9$)$ & $74.5(67.0$ to 81.9$)$ \\
\hline 12 months & 69.6 (61.9 to 77.3$)$ & 80.2 (73.5 to 86.9$)$ \\
\hline \multicolumn{3}{|c|}{ Quality of Life (EQ-5D-3L, -0.5 to $1.0 ; 1=$ best) } \\
\hline Baseline & 0.7 (0.6 to 0.8$)$ & 0.7 (0.6 to 0.8$)$ \\
\hline 2 months & 0.7 (0.7 to 0.8$)$ & 0.8 (0.7 to 0.9$)$ \\
\hline 3 months & 0.8 (0.7 to 0.8$)$ & 0.8 (0.8 to 0.9$)$ \\
\hline 6 months & 0.8 (0.7 to 0.9$)$ & 0.8 (0.8 to 0.9$)$ \\
\hline 12 months & 0.8 (0.8 to 0.9$)$ & 0.9 (0.8 to 0.9$)$ \\
\hline \multicolumn{3}{|c|}{$\begin{array}{l}\text { Visual Analogue Scale for quality of life (EQ-5D-3L, 0-100; } \\
100=\text { best) }\end{array}$} \\
\hline Baseline & 72.9 (68.3 to 77.5$)$ & 70.2 (64.1 to 76.4$)$ \\
\hline 2 months & 78.3 (73.5 to 82.0$)$ & $80.2(76.3$ to 84.1$)$ \\
\hline 3 months & 79.3 (75.2 to 83.5 ) & 82.4 (77.4 to 87.4$)$ \\
\hline
\end{tabular}

Continued
Table 2 Continued

\begin{tabular}{cll}
\hline & \multicolumn{2}{c}{ Intervention group } \\
\cline { 2 - 3 } Outcome measure & Placebo & $\begin{array}{l}\text { Omega-3 } \\
\text { polyunsaturated } \\
\text { fatty acids }\end{array}$ \\
\hline 6 months & $82.8(79.5$ to 86.0$)$ & $82.2(78.0$ to 86.3$)$ \\
\hline 12 months & $78.7(71.3$ to 86.0$)$ & $79.1(73.4$ to 84.9$)$ \\
\hline Global perception of change (0-100; $100=$ best) \\
\hline 2 months & $54.1(43.8$ to 64.4$)$ & $55.3(45.4$ to 65.2$)$ \\
\hline 3 months & $66.1(58.3$ to 74.0$)$ & $70.8(61.9$ to 79.7$)$ \\
\hline 6 months & $75.6(68.2$ to 82.9$)$ & $74.2(63.2$ to 85.2$)$ \\
12 months & $80.0(72.2$ to 87.8$)$ & $78.0(66.9$ to 89.1$)$ \\
\hline
\end{tabular}

Summary measures are means (95\% Cls) analysed using independent samples t-test and between-group comparison by univariate analysis of covariance adjusted for baseline value, age, gender and body mass index.

${ }^{*}$ Represents a statistically significant difference

omega- 3 fatty acids would be close to $3 \mathrm{~g}$ /day, the level where triglyceride lowering effects are noted as well as effects on blood pressure. With allowance for incomplete consumption (eight vs nine capsules/day), this still would provide a total intake of $2.7 \mathrm{~g} /$ day of omega-3 fatty acids. While higher intakes of omega- 3 might have greater anti-inflammatory effects, the safety of higher intakes taken for long periods of time is less established.

\section{LIMITATIONS}

Two months supplementation was selected due to evidence suggesting that there is a maximal incorporation into the plasma phospholipids at 4 weeks. ${ }^{32}{ }^{33}$ The positive results reported by Mavrogenis $e t a l^{23}$ were seen at 32 days, which was half the duration of the intervention and first outcome point of the current study. However,

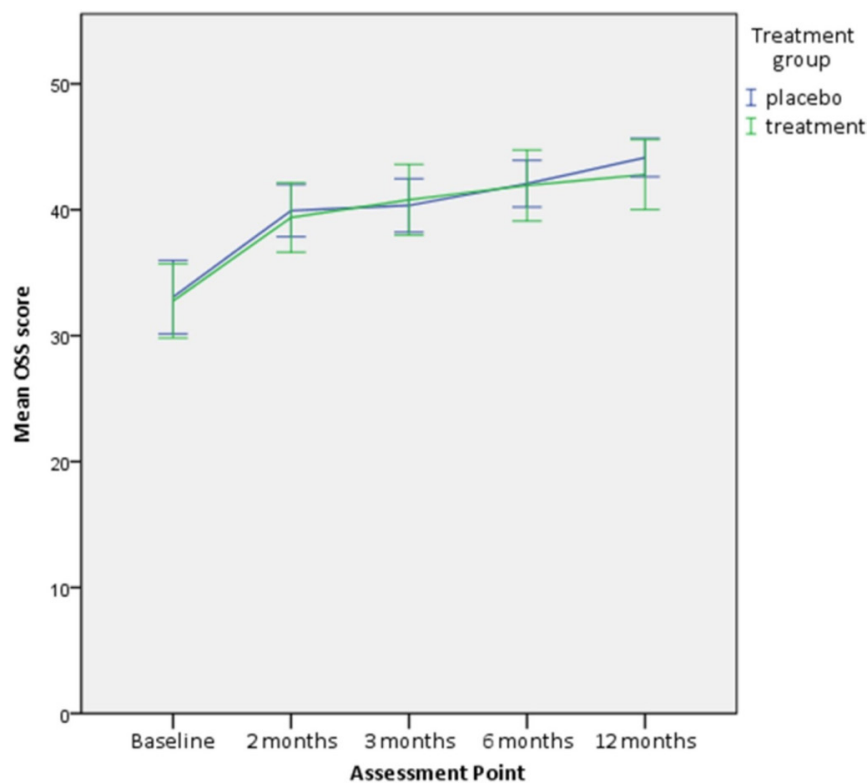

Figure 3 Oxford Shoulder Score (OSS) at each assessment point. Error bars $=95 \% \mathrm{Cl}$. 


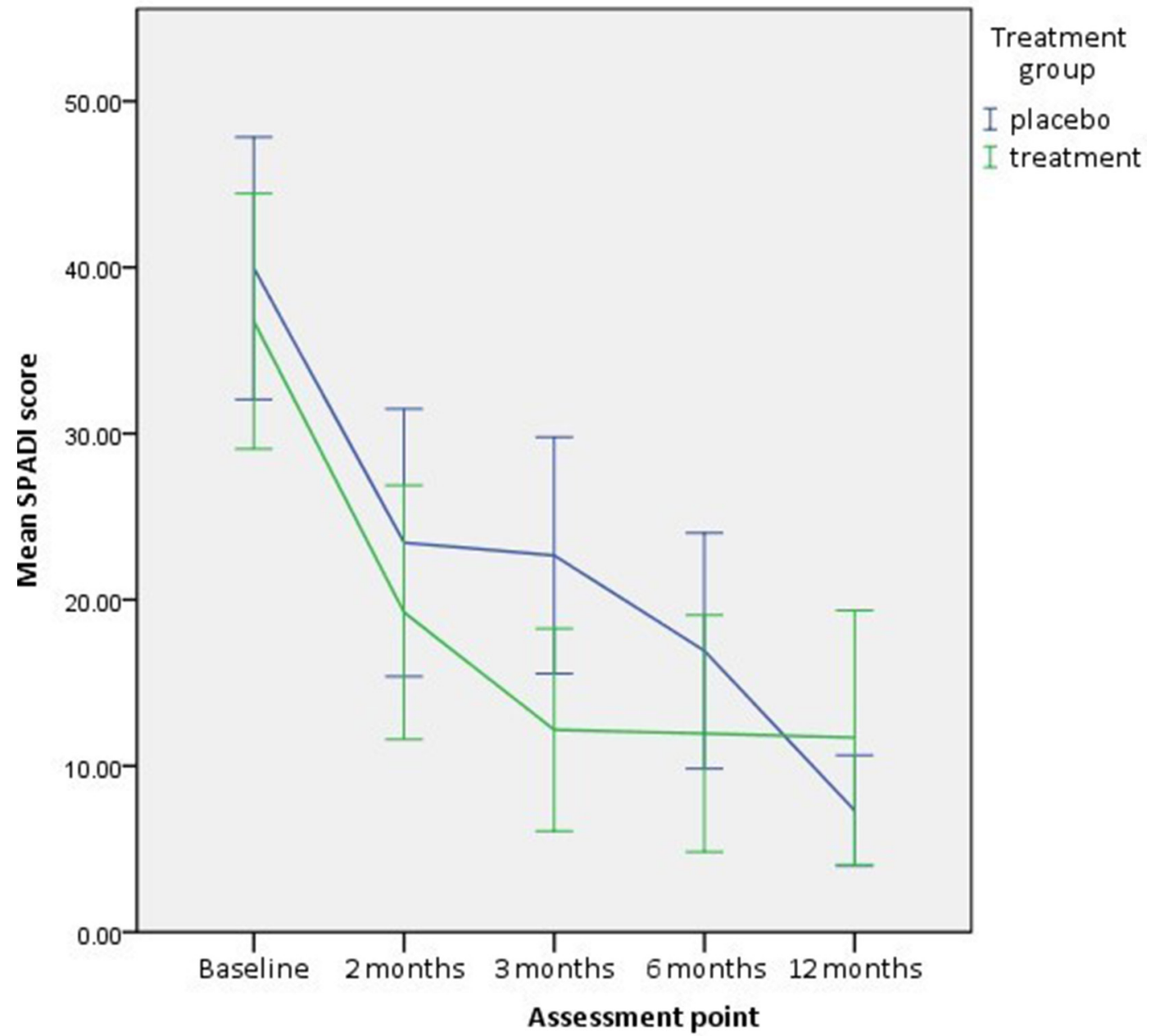

Figure 4 Shoulder Pain and Disability Index (SPADI) at each assessment point. Error bars = 95\% Cl.

in trials of omega-3 PUFAs for rheumatoid arthritis and osteoarthritis, supplementation duration can last up to 6 months. It is not possible to say whether ongoing supplementation or a higher dose would have afforded any additional benefit in this study.

Improvement in disability associated with attendance to the exercise group may have overshadowed any change in disability directly associated with omega-3 PUFA supplement use. However, a well-structured exercise programme is current best practice intervention for RCRSP $^{1}$ and subsequently potentially unethical to withdraw this intervention.

Possibly that the OSS was not sensitive enough to detect any change attributable to the omega-3 PUFA supplements. A statistically significant difference in reduction in disability (as measured by SPADI) was seen at 3 months but not mirrored in the OSS. This is despite reported good correlation between the OSS and SPADI (correlation coefficient $=0.85$ ) and good agreement between the scores (weighted kappa $=0.79$ ). ${ }^{34}$ The recall period of the two questionnaires may explain the difference. The SPADI asks the respondent to recall symptoms during the past week, whereas the OSS asks the respondent to recall symptoms over the past 4 weeks. Between the primary outcome point at 2 months and the subsequent follow-up at 3 months, there was only a 4 -week break. It is possible that any additional benefit experienced between 2 and 3 months was not recorded by the OSS due to the duration of the recall period. Although questionable whether a difference of 8.25 observed between the groups in the SPADI at 3 months is clinically meaningful when the minimal clinically important difference (MCID) of the SPADI has been reported to range from 8 to $20 .^{35-38}$ Similarly, this finding may have occurred by chance, especially as the difference was not sustained.

Assessments were carried out by more than one examiner which may have introduced measurement error. The intertester reliability of the impairment measures by the examiners was found to be adequate (table 3$).^{39}$ As for the SPADI, the primary outcome measure was the OSS, a self-administrated questionnaire, and as such, it is unlikely that the results would be influenced by a change in the examiner.

\section{CONCLUSION}

The findings of this randomised placebo controlled trial suggest that an exercise program combined with $9 \mathrm{~g} /$ day (2.6 g EPA and DHA) of omega-3 PUFA for 8 weeks 
Table 3 Impairment measures during the course of the trial Intervention group

\begin{tabular}{lll}
\cline { 2 - 3 } $\begin{array}{l}\text { Outcome } \\
\text { measure }\end{array}$ & Placebo & $\begin{array}{l}\text { Omega-3 polyunsaturated } \\
\text { fatty acid }\end{array}$ \\
\hline
\end{tabular}

Symptomatic GHJ flexion (measured in degrees)

\begin{tabular}{|lll}
\hline Baseline & $141.1(134.2$ to 148.0$)$ & $140.4(134.6$ to 146.2$)$ \\
\hline months & $144.5(137.9$ to 151.1$)$ & $145.2(139.1$ to 151.3$)$ \\
\hline months & $146.6(142.0$ to 151.2$)$ & $152.8^{*}(148.6$ to 157.0$)$ \\
\hline 12 months & $150.6(144.9$ to 156.3$)$ & $151.1(145.6$ to 156.6$)$ \\
\hline
\end{tabular}

Symptomatic GHJ abduction (measured in degrees)

\begin{tabular}{|c|c|c|}
\hline Baseline & $134.6(125.2$ to 144.0$)$ & 131.5 (122.6 to 140.4$)$ \\
\hline 2 months & $144.3(137.4$ to 151.2$)$ & $138.1(130.3$ to 145.9$)$ \\
\hline 3 months & $140.4(133.5$ to 147.3$)$ & $148.4^{*}(144.0$ to 152.8$)$ \\
\hline 6 months & $149.2(142.9$ to 155.5$)$ & $148.1(142.2$ to 154.0$)$ \\
\hline 12 months & $146.1(139.7$ to 152.5$)$ & $150.8(145.3$ to 156.3$)$ \\
\hline \multicolumn{3}{|c|}{ Symptomatic GHJ external rotation (measured in $\mathrm{cm}$ ) } \\
\hline Baseline & 41.1 (39.2 to 43.0$)$ & 39.3 (37.4 to 41.2$)$ \\
\hline 2 months & 41.4 (39.4 to 43.3$)$ & 40.5 (39.0 to 42.1$)$ \\
\hline 3 months & 42.0 (39.6 to 44.4$)$ & 41.9 (39.9 to 43.9$)$ \\
\hline 6 months & $42.4(40.1$ to 44.7$)$ & 40.6 (38.2 to 43.0$)$ \\
\hline 12 months & 44.0 (42.0 to 46.0$)$ & 42.4 (40.5 to 44.3$)$ \\
\hline
\end{tabular}

Symptomatic GHJ hand behind back (measured in $\mathrm{cm}$ )

\begin{tabular}{lll} 
Baseline & $31.0(27.6$ to 34.4$)$ & $30.8(26.9$ to 34.7$)$ \\
\hline 2 months & $28.3(24.8$ to 31.8$)$ & $28.6(22.9$ to 28.7$)$ \\
3 months & $27.5(24.0$ to 31.0$)$ & $25.8(22.6$ to 29.0$)$ \\
6 months & $26.2(23.3$ to 29.0$)$ & $24.6(22.4$ to 26.8$)$ \\
12 months & $24.8(21.2$ to 28.4$)$ & $23.4(20.8$ to 26.0$)$
\end{tabular}

Symptomatic GHJ flexion strength (measured in pounds)

\begin{tabular}{lll} 
Baseline & $21.6(19.6$ to 23.6$)$ & $21.1(17.7$ to 24.5$)$ \\
\hline 2 months & $24.5(22.1$ to 26.9$)$ & $22.8(19.4$ to 26.2$)$ \\
\hline 3 months & $25.2(22.6$ to 27.8$)$ & $22.1(18.5$ to 25.7$)$ \\
\hline months & $27.1(24.4$ to 29.6$)$ & $26.4(22.6$ to 30.2$)$ \\
\hline 12 months & $26.6(23.6$ to 29.6$)$ & $25.6(27.2$ to 29.0$)$
\end{tabular}

Symptomatic GHJ abduction strength (measured in pounds)

\begin{tabular}{|lll|}
\hline Baseline & $21.6(18.6$ to 24.6$)$ & $19.3(16.6$ to 22.0$)$ \\
\hline 2 months & $25.7(22.7$ to 28.7$)$ & $22.4(19.2$ to 25.6$)$ \\
\hline 6 months & $25.6(22.3$ to 28.9$)$ & $22.3(18.9 \backslash$ to 25.7$)$ \\
\hline 12 months & $26.7(24.1$ to 29.3$)$ & $24.9(21.7$ to 28.1$)$ \\
\hline
\end{tabular}

Symptomatic full can strength (measured in pounds)

\begin{tabular}{|c|c|c|}
\hline Baseline & $9.4(7.6$ to 11.2$)$ & $8.3(6.4$ to 10.2$)$ \\
\hline 2 months & $11.4(9.4$ to 13.4$)$ & $10.2(7.8$ to 12.6$)$ \\
\hline 3 months & $12.2(10.0$ to 14.4$)$ & $10.8(8.1$ to 13.5$)$ \\
\hline 6 months & $12.4(10.3$ to 14.5$)$ & 11.7 (9.3 to 14.1$)$ \\
\hline 12 months & 13.0 (11.2 to 14.8$)$ & $12.6(10.2$ to 15.0$)$ \\
\hline \multicolumn{3}{|c|}{ Symptomatic empty can strength (measured in pounds) } \\
\hline Baseline & 9.1 (7.6 to 10.6$)$ & 7.5 (5.8 to 9.2$)$ \\
\hline 2 months & $11.8(10.0$ to 13.6$)$ & $10.3(8.1$ to 12.5$)$ \\
\hline 3 months & 12.6 (10.7 to 14.5$)$ & 9.9 (7.6 to 12.2$)$ \\
\hline
\end{tabular}

Continued
Table 3 Continued

\begin{tabular}{|c|c|c|}
\hline \multirow[b]{2}{*}{$\begin{array}{l}\text { Outcome } \\
\text { measure }\end{array}$} & \multicolumn{2}{|l|}{ Intervention group } \\
\hline & Placebo & $\begin{array}{l}\text { Omega- } 3 \text { polyunsaturated } \\
\text { fatty acid }\end{array}$ \\
\hline 6 months & 13.1 (11.3 to 14.9$)$ & 11.5 (9.3 to 13.7$)$ \\
\hline 12 months & $14.3(11.5$ to 17.1$)$ & $12.8(10.6$ to 15.0$)$ \\
\hline \multicolumn{3}{|c|}{ Symptomatic external rotation strength (measured in pounds) } \\
\hline Baseline & $15.4(13.3$ to 17.5$)$ & 12.7 (10.8 to 14.6$)$ \\
\hline 2 months & 16.8 (14.8 to 18.8$)$ & $15.6(13.2$ to 18.0$)$ \\
\hline 3 months & 17.8 (15.5 to 20.1$)$ & 16.2 (13.5 to 18.9$)$ \\
\hline 6 months & 18.7 (16.6 to 20.8$)$ & 16.7 (14.3 to 19.1$)$ \\
\hline 12 months & 17.8 (15.9 to 19.7$)$ & $18.7^{*}(16.3$ to 21.1$)$ \\
\hline \multicolumn{3}{|c|}{ Symptomatic internal rotation strength (measured in pounds) } \\
\hline Baseline & $19.2(16.5$ to 21.9$)$ & 16.9 (14.3 to 19.5$)$ \\
\hline 2 months & 22.1 (20.1 to 26.1$)$ & 19.1 (15.9 to 22.3$)$ \\
\hline 3 months & 23.8 (20.4 to 27.2$)$ & 21.4 (17.5 to 25.3$)$ \\
\hline 6 months & 24.3 (20.8 to 27.8$)$ & 20.7 (17.1 to 24.3$)$ \\
\hline 12 months & 24.6 (21.5 to 27.7$)$ & 23.1 (19.4 to 26.8$)$ \\
\hline \multicolumn{3}{|c|}{ Symptomatic elbow flexion strength (measured in pounds) } \\
\hline Baseline & 26.7 (21.8 to 31.6$)$ & $25.2(20.4$ to 30.0$)$ \\
\hline 2 months & $31.3(26.7$ to 35.9$)$ & 29.4 (24.2 to 34.6$)$ \\
\hline 3 months & 32.9 (27.6 to 38.2$)$ & $30.3(24.1$ to 36.5$)$ \\
\hline 6 months & 32.6 (27.9 to 37.3$)$ & 33.0 (27.5 to 38.5$)$ \\
\hline 12 months & 33.3 (27.4 to 39.2$)$ & $31.7(26.3$ to 37.1$)$ \\
\hline
\end{tabular}

Summary measures are means ( $95 \% \mathrm{Cls}$ ) analysed using independent samples t-test and between-group comparison by univariate analysis of covariance adjusted for baseline value, age, gender and body mass index.

*represents a statistically significant difference

GHJ, Gleno humeral joint.

provides no additional benefit when compared with the same exercise program when combined with a placebo supplement over the course of one year, for those diagnosed with RCRSP. The finding that at 3-months a significant reduction in disability (as measured by the SPADI) in the omega-3 group warrants further investigation, but this finding does not currently support the use of omega-3 PUFA supplementation in this condition. With acknowledged limitations, such as no control group, the findings of this investigation suggest participation in a graduated exercise program is associated with a substantial reduction in disability and improvement in function for people diagnosed with RCRSP.

Acknowledgements The authors thank all the patient advisers, participants, physiotherapists, clinical research nurses and Rashida Pickford, Sarah Friel, Abdel Douri and Robert Gray who contributed to this trial. The authors also thank all physiotherapy departments who participated in this trial namely;St Thomas', Guys, St Georges and Central London Community Healthcare NHS Trust. The authors would also like to thank Seven Seas Ltd who provided both the active and placebo capsules. Seven Seas Ltd had no other involvement with the study other than capsule issue and checking the capsule quality at the end of the study.

Contributors The initial idea for this study was generated by JL. FS, TS and JL have contributed to the planning of the manuscript and the planning of the study. FS has written the paper and this has been reviewed by all contributing authors. Data collection was conducted by HW and FS. 
Funding Seven Seas Ltd provided the active and placebo capsules for this study. There was no other funding for this study.

Competing interest None declared.

Patient consent Obtained.

Provenance and peer review Not commissioned; externally peer reviewed.

Data sharing statement There is no additional information to be made available for data sharing.

Open access This is an open access article distributed in accordance with the Creative Commons Attribution Non Commercial (CC BY-NC 4.0) license, which permits others to distribute, remix, adapt, build upon this work non-commercially, and license their derivative works on different terms, provided the original work is properly cited, appropriate credit is given, any changes made indicated, and the use is non-commercial. See: http://creativecommons.org/licenses/by-nc/4.0/

\section{REFERENCES}

1. Lewis J, McCreesh K, Roy JS, et al. Rotator cuff tendinopathy: navigating the diagnosis-management conundrum. J Orthop Sports Phys Ther 2015;45:923-37.

2. Chard MD, Hazleman R, Hazleman BL, et al. Shoulder disorders in the elderly: a community survey. Arthritis Rheum 1991;34:766-9.

3. Luime JJ, Koes BW, Hendriksen IJ, et al. Prevalence and incidence of shoulder pain in the general population: a systematic review. Scand J Rheumatol 2004;33:73-81.

4. Chaudhury S, Gwilym SE, Moser J, et al. Surgical options for patients with shoulder pain. Nat Rev Rheumatol 2010;6:217-26.

5. Tashjian RZ. Epidemiology, natural history, and indications for treatment of rotator cuff tears. Clin Sports Med 2012;31:589-604.

6. Ainsworth R, Lewis J, Conboy V. A prospective randomized placebo controlled clinical trial of a rehabilitation programme for patients with a diagnosis of massive rotator cuff tears of the shoulder. Shoulder Elbow 2009;1:55-60.

7. Holmgren $\mathrm{T}$, Björnsson Hallgren $\mathrm{H}$, Öberg B, et al. Effect of specific exercise strategy on need for surgery in patients with subacromial impingement syndrome: randomised controlled study. BMJ 2012;344:e787.

8. Litchfield R. Progressive strengthening exercises for subacromial impingement syndrome. Clin J Sport Med 2013;23:86-7.

9. Macfarlane GJ, Hunt IM, Silman AJ. Predictors of chronic shoulder pain: a population based prospective study. J Rheumatol 1998;25:1612-5

10. Rees JD, Maffulli N, Cook J. Management of tendinopathy. Am J Sports Med 2009;37:1855-67-

11. Matthews TJ, Hand GC, Rees JL, et al. Pathology of the torn rotator cuff tendon. Reduction in potential for repair as tear size increases. Bone Joint Surg Br 2006;88:489-95.

12. Millar NL, Hueber AJ, Reilly JH, et al. Inflammation is present in early human tendinopathy. Am J Sports Med 2010;38:2085-91.

13. Gotoh M, Hamada K, Yamakawa H, et al. Significance of granulation tissue in torn supraspinatus insertions: an immunohistochemical study with antibodies against interleukin-1 beta, cathepsin D, and matrix metalloprotease-1. J Orthop Res 1997;15:33-9.

14. Andersson $G$, Backman LJ, Scott $A$, et al. Substance $P$ accelerates hypercellularity and angiogenesis in tendon tissue and enhances paratendinitis in response to Achilles tendon overuse in a tendinopathy model. Br J Sports Med 2011:45:1017-22.

15. Pingel J, Wienecke J, Kongsgaard M, et al. Increased mast cell numbers in a calcaneal tendon overuse model. Scand J Med Sci Sports 2013;23:e353-e360.

16. Voloshin I, Gelinas J, Maloney MD, et al. Proinflammatory cytokines and metalloproteases are expressed in the subacromial bursa in patients with rotator cuff disease. Arthroscopy 2005;21:1076. e1-1076.e9.

17. Blaine TA, Kim YS, Voloshin I, et al. The molecular pathophysiology of subacromial bursitis in rotator cuff disease. J Shoulder Elbow Surg 2005;14(1 Suppl S):S84-S89.
18. Sakai H, Fujita K, Sakai Y, et al. Immunolocalization of cytokines and growth factors in subacromial bursa of rotator cuff tear patients. Kobe J Med Sci 2001;47:25-34

19. Haahr JP, Andersen JH. Exercises may be as efficient as subacromial decompression in patients with subacromial stage II impingement: 4-8-years' follow-up in a prospective, randomized study. Scand J Rheumatol 2006;35:224-8.

20. Ketola S, Lehtinen J, Rousi T, et al. No evidence of long-term benefits of arthroscopicacromioplasty in the treatment of shoulder impingement syndrome: five-year results of a randomised controlled trial. Bone Joint Res 2013;2:132-9.

21. Lewis JS, Sandford FM. Rotator cuff tendinopathy: is there a role for polyunsaturated fatty acids and antioxidants? J Hand Ther 2009;22:49-56.

22. Calder PC. Fatty acids and inflammation: the cutting edge between food and pharma. Eur J Pharmacol 2011;668(Suppl 1):S50-S58.

23. Mavrogenis $S$. The effect of essential fatty acids and antioxidants combined with physiotherapy treatment in recreational athletes with chronic tendon disorders: a randomised, double-blind, placebocontrolled study. Phys Ther Sport 2004;5:194-9.

24. Røe C, Ødegaard TT, Hilde F, et al. [No effect of supplement of essential fatty acids on lateral epicondylitis]. Tidsskr Nor Laegeforen 2005;125:2615-8.

25. Ainsworth R. Physiotherapy rehabilitation in patients with massive, irreparable rotator cuff tears. Musculoskeletal Care 2006;4:140-51.

26. van Kampen DA, Willems WJ, van Beers LW, et al. Determination and comparison of the smallest detectable change (SDC) and the minimal important change (MIC) of four-shoulder patient-reported outcome measures (PROMs). J Orthop Surg Res 2013;8: :40.

27. Elkins MR, Moseley AM. Intention-to-treat analysis. J Physiother 2015;61:165-7.

28. Bartolozzi A, Andreychik D, Ahmad S. Determinants of outcome in the treatment of rotator cuff disease. Clin Orthop Relat Res 1994:308:90-7.

29. Krogsbøll LT, Hróbjartsson A, Gøtzsche PC. Spontaneous improvement in randomised clinical trials: meta-analysis of three-armed trials comparing no treatment, placebo and active intervention. BMC Med Res Methodol 2009;9:1.

30. Geusens P, Wouters C, Nijs J, et al. Long-term effect of omega-3 fatty acid supplementation in active rheumatoid arthritis. Arthritis Rheum 1994;37:824-9.

31. Al-Hilal M, Alsaleh A, et al. MARINA study team. Genetic variation at the FADS1-FADS2 gene locus influences delta-5 desaturase activity and LC-PUFA proportions after fish oil supplement. J Lipid Res 2013:54:542-51.

32. Yaqoob P, Pala HS, Cortina-Borja M, et al. Encapsulated fish oi enriched in alpha-tocopherol alters plasma phospholipid and mononuclear cell fatty acid compositions but not mononuclear cell functions. Eur J Clin Invest 2000;30:260-74.

33. Healy DA, Wallace FA, Miles EA, et al. Effect of low-to-moderate amounts of dietary fish oil on neutrophil lipid composition and function. Lipids 2000;35:763-8

34. Cloke DJ, Lynn SE, Watson $\mathrm{H}$, et al. A comparison of functional, patient-based scores in subacromial impingement. J Shoulder Elbow Surg 2005;14:380-4

35. Schmitt JS, Di Fabio RP. Reliable change and minimum important difference (MID) proportions facilitated group responsiveness comparisons using individual threshold criteria. J Clin Epidemiol 2004:57:1008-18.

36. Paul A, Lewis M, Shadforth MF, et al. A comparison of four shoulder-specific questionnaires in primary care. Ann Rheum Dis 2004;63:1293-9.

37. Williams JW, Holleman DR, Simel DL. Measuring shoulder function with the Shoulder Pain and Disability Index. J Rheumato 1995;22:727-32

38. Ekeberg OM, Bautz-Holter E, Keller A, et al. A questionnaire found disease-specific WORC index is not more responsive than SPADI and OSS in rotator cuff disease. J Clin Epidemiol 2010;63:575-84.

39. Dollings $\mathrm{H}$, Sandford $\mathrm{F}, \mathrm{O}^{\prime}$ conaire $\mathrm{E}$, et al. Shoulder strength testing: the intra- and inter-tester reliability of routine clinical tests, using the Powertrack TM II Commander. Shoulder Elbow 2012;4:131-40. 